\title{
Sobre la transformación del paradigma de la seguridad
}

doi: http://dx.doi.org/10.32870/espiral.v23i66.5305.g4932 Fredyd Torres Oregón •

La seguridad ciudadana es uno de los conceptos en construcción que adopta la visión integral de otorgar todos los satisfactores a los ciudadanos. Deriva del respeto a los derechos humanos y de una mirada integral para entender el pacto social. Surge de los organismos internacionales como la Organización de las Naciones Unidas y la Comisión Interamericana de los Derechos Humanos, entre otros, que consideran una ruptura en los mecanismos tradicionales del otorgamiento de la seguridad mediante la coerción y el uso de la fuerza, ante los cuales ahora se promueven las políticas ex ante, es decir, la prevención. Dicha corriente propone como paradigma la participación ciudadana en las funciones para disminuir y atenuar los factores que propician la violencia y la delincuencia. La finalidad del estudio de esto estaría en describir cómo se puede adoptar esta nueva visión desde un punto de partida holístico, multidisciplinario y sistémico, en el cual se incluya a los ciudadanos y las instituciones que imparten justicia, y no sólo a los policías.

En ese contexto, el trabajo aquí reseñado

Profesor-Investigador del Centro de Estudios e Investigación en Desarrollo Sustentable de la Universidad Autónoma del Estado de México (UAEMEX).

zancamx@yahoo.com.mx devela la incapacidad de la policía para enfrentar las bandas criminales por la falta de coordinación, capacitación, profesionalización y la corrupción existente.

José Luis Estrada Rodríguez (coord.) (2014). Seguridad ciudadana: visiones compartidas. México: Universidad Autónoma del Estado de México, Instituto de Administración Pública del Estado de México. 
Pone de relieve las carencias en torno a equipamiento y la necesidad de contar con inteligencia policial para abatir los delitos más agudos vinculados con el tráfico de estupefacientes. Teniendo como antecedente las políticas de prevención desarrolladas en Colombia, Argentina y Brasil, desmenuza su metodología aplicada al caso mexicano, hasta ahora con pocos resultados, por lo cual describe cuáles han sido las inconsistencias en las políticas de seguridad aplicadas en México.

Los autores del libro coinciden con la visión que plantea en el concepto de seguridad ciudadana dos visiones predominantes: una normativa, a partir de la cual se establece lo que debería de ser la actuación de los ciudadanos; y otra visión que se enfoca en la creación, implementación y evaluación de políticas públicas para contrarrestar la inseguridad y la violencia (Moriconi Bezerra, 2011, p. 619). Esta obra es resultado de la experiencia de los investigadores en el desarrollo de programas de prevención aplicados en todo el país, investigadores que pretenden documentar estas aportaciones para familiarizar a los Gobiernos subnacionales sobre la factibilidad de avanzar en ese sentido.

El libro está dividido en tres grandes temas: en la primera parte, epistemología de la violencia y la delincuencia; en la segunda, debate actual de la seguridad ciudadana; y en la tercera parte se aborda la metodología aplicada a temas de seguridad ciudadana y se presenta un compendio de análisis realizados por especialistas regionales que toman el caso de México sobre la estrategia nacional para la prevención social de la violencia y la delincuencia anunciada por el presidente Enrique Peña en 2014, y que establece catorce estrategias y noventa y ocho líneas de acción. A partir de una visión multidisciplinaria, los autores adoptan una visión crítica sobre el tema de la seguridad ciudadana, los retos para transformar el papel de la policía y los elementos detonantes de la violencia en nuestro país. 
En la primera parte, se describe a la violencia, así como la delincuencia protagonizada por bandas criminales y cárteles, en constante transformación. "Las perspectivas más contemporáneas subrayan la necesidad de dar cuenta de la violencia como un proceso en el que juega un papel central la construcción de sentido" (p. 21). En el texto, se profundiza en la complejidad sobre cómo la delincuencia se apropia de estas políticas de miedo para establecer control y vulnerar, incluso al propio Estado.

La violencia es un elemento que debe erradicarse, coinciden los autores clásicos de la sociología, pero también alertan sobre las tensiones existentes en la socialización de los sujetos. Los actores sociales actúan en torno a la exclusión, a la violencia estructural y, sobre todo, a la conceptualización de sus miedos, metas y valores. Estamos viviendo una nueva manera de entender la violencia, vinculada con la satisfacción de ciertas necesidades, incentivos de dominación, explotación, respeto y seguridad. Uno de los retos que plantea este libro es pasar de la descripción de los casos y las estadísticas al establecimiento de los factores que detonan la violencia, todo esto para tratar de aislar los factores y proponer soluciones.

En el debate que alimenta el nuevo paradigma de la seguridad ciudadana, se contempla avanzar en torno al fortalecimiento y la transformación profunda de las instituciones de justicia, pero, más importante, promover la cultura de la legalidad y el combate a la corrupción. El control del crimen organizado deberá ser también a partir de un sistema efectivo de las fuerzas armadas: no todo puede ser prevención cuando estamos viviendo la urgente necesidad de restablecer la paz y el Estado de derecho con instituciones fuertes, incorruptibles y eficientes.

En la segunda parte del libro, se profundiza en torno al debate actual de la seguridad ciudadana. Se describe cómo el incremento en el presupuesto de las fuerzas armadas, 
desde que en 2006 el presidente Felipe Calderón declaró la guerra contra el narcotráfico, no ha llevado a resultados alentadores por la falta de estrategia y la carencia de mecanismos institucionales para mejorar el eslabón perdido de la policía: vínculo entre ciudadanos y Gobierno. Es decir, el incremento de la inversión para las fuerzas armadas produjo más violencia e inseguridad si se atiende a las cifras de homicidios y muertes vinculadas con el narcotráfico, que se incrementaron, desvirtuando así la correlación entre inversión y disminución de los delitos vinculados con el tráfico de estupefacientes.

Asimismo, en este segundo apartado se aborda el paradigma de la seguridad ciudadana y el papel del Estado como garante de la seguridad de los individuos, hoy en día cuestionado por el incremento de la violencia y la delincuencia. Se rescata la génesis del Estado-nación para describir, a partir de los teóricos como Weber, Hobbes, Rousseau y otros, las características del contrato social y justificación del Estado. Ante el resquebrajamiento de este pacto dada la incapacidad del Estado para otorgar seguridad en todos los sentidos a los ciudadanos, la perspectiva de la seguridad ciudadana se impone como una forma de incluir a todos en las tareas de prevención. Se transforma por tanto el paradigma punitivo, de encarcelamiento y coercitivo, en intervención social y prevención de la violencia. Todo esto sin olvidar que debe tenerse un Estado fuerte para contrarrestar a quienes están dispuestos a enfrentar al Gobierno y, por otro lado, establecer mecanismos para construir un Estado social que atienda las demandas de los ciudadanos y promueva el restablecimiento de la ciudadanía.

La obra muestra que las experiencias en América Latina, principalmente en Brasil, señalan que incorporar a los ciudadanos en las tareas de prevención y rescate de los barrios es el mejor ejemplo de gobernanza y de control por parte de las autoridades con el apoyo de los propios pobladores. 
La policía cercana con tareas disuasivas y de apropiación de los barrios y territorios ocupados por los delincuentes emerge de este paradigma de la seguridad ciudadana. Se documenta cómo el rescate de la cohesión social, la integración ciudadana y el desarrollo de pautas de convivencia armónica se han incorporado al tema de la prevención social de la violencia como factores preventivos.

La función y operación policial muestra cambios. Su objetivo ha sido otorgar mayores capacidades institucionales para los Gobiernos subnacionales, pero existe además el tema de la violencia en todas sus acepciones, que el libro también aborda. Uno de los temas al respecto es la violencia de género: "el acto de violencia es claro en la subjetivación de los roles masculino-femenino. Se ejerce la violencia hacia las mujeres con su complicidad y consentimiento" (p. 162). El análisis va desde la violencia simbólica ejercida hacia las mujeres, hasta la violencia institucional. El trabajo de los investigadores que participan resulta muy completo por el intrincado viaje de la violencia que es reforzado por la televisión, los medios de comunicación, la cultura y las tradiciones. Los intercambios sociales resultan también violentos: la discriminación social, exclusión y violencia política, pasan a ser un mecanismo para detonar el miedo, bajo formas relativamente inéditas, como Augé (2015) describe, coincidiendo con esta obra.

Finalmente, en el tercer apartado se describen diversas metodologías vinculadas con el análisis de la violencia y la delincuencia. Los jóvenes son el grupo que se encuentra más vulnerable a la violencia. Es plausible asumir que las cifras de homicidios y muertes vinculadas con la delincuencia organizada han disminuido de 27213 homicidios, en 2011, a 19 811, en 2014, como muestra Guerrero (2015). Sin embargo, la geografía de la violencia y la delincuencia, producto de los análisis realizados en los observatorios, muestra incremento en otro tipo de delitos como el secuestro 
y la extorsión. En particular, en el libro se describe la experiencia de construir el Observatorio de Seguridad Pública del Estado de México, así como algunos de sus hallazgos más importantes: la población no conoce sus derechos y existen instituciones débiles en torno a la aplicación de la ley y la justicia, así como una percepción de la violencia y la delincuencia vinculada con los medios de comunicación.

Para tener información que permita disminuir los delitos es necesario reunirla, recopilar datos de campo. Entender el modus operandi. En este tercer capítulo se describe cómo el mapa delincuencial es distinto por su manera de interactuar. El diagnóstico muestra cómo en el Valle de México existe cohabitación con los delincuentes. Es decir, las familias están vinculas con los ilícitos. En el Valle de Toluca persiste la delincuencia común (robo de vehículos, robo a transeúnte, a casa habitación, etc.), en tanto que en el sur del Estado de México operan grupos criminales, crimen organizado y grupos paramilitares, autodefensas incluso. El libro ofrece un diagnóstico real derivado de encuestas y entrevistas. Su aporte es significativo para los tomadores de decisiones y resulta un documento valioso para comprender el desarrollo de la inestabilidad que se vive no sólo en la entidad mexiquense, sino en todo el país.

La distinción del paradigma de la seguridad ciudadana de la concepción anterior de seguridad pública se basa en establecer un análisis de los elementos que promueven o detonan la violencia en todos sus ámbitos. El combate al delito es una tarea muy compleja que sólo puede lograrse con la integración de la fuerza pública, pero también con todos los elementos contenedores de la violencia: la religión, las organizaciones, la educación, etcétera.

Este libro resulta aleccionador para elaborar políticas públicas, programas de prevención y promover la evaluación a partir de observatorios, como describe el análisis empírico realizado. Es provocador porque descubre las distintas 
violencias, no sólo desde la delincuencia organizada, sino también desde los mecanismos institucionales, y propone enriquecer el paradigma de la seguridad ciudadana a partir de la cultura de la legalidad y el rediseño de las instituciones de justicia, así como del papel del Estado como garante de la seguridad.

Augé, M. (20I5). Los nuevos miedos. México: Editorial Paidós. Bibliografía Guerrero, E. (02 de enero de 20I5). “¿Bajó la violencia?”. Nexos. Recuperado de: http://www.nexos.com.mx Moriconi Bezerra, M. (20II). "Desmitificar la violencia: crítica al discurso (técnico) de la seguridad ciudadana”. Revista Mexicana de Sociología, 73(4), 6I7-643.

Orlando, L. (2010). Hacia una cultura de la legalidad. La experiencia siciliana. México: Universidad Autónoma Metropolitana. 